\title{
The Human Mammary-Derived Grow th Inhibitor (MDGI) Gene: Genomic Structure and Mutation Analysis in Human Breast Tumors
}

\author{
Catherine M. Phelan, $* \dagger^{\prime 1}$ Catharina Larsson, $*$ Stephen Baird, $\ddagger$ P. Andrew Futreal, $\$$ \\ M. H. Ruttledge, $₫$ Kenneth Morgan,† Patricia Tonin, $\dagger$ Huynh Hung," \\ Robert G. KORNELUK, $\ddagger$ MichaEl N. POLlak, $\|, * *$ \\ and SteVEn A. NAROd†
}

* Department of Molecular Medicine, Endocrine Tumour Unit, Karolinska Hospital, Stockholm, Sweden; †Departments of Human Genetics and Medicine, McGill University and Montreal General Hospital Research Institute, Montreal, Quebec, Canada;

$\ddagger$ Molecular Genetics Laboratory, Childrens Hospital of Eastern Ontario, Ottawa, Ontario, Canada;

$\S$ Department of Surgery and Genetics, Duke University Medical Centre, Durham, North

Carolina; đCentre for Research and Neuroscience, Montreal General Hospital,

Quebec, Canada; "Lady Davis Research Institute, M ontreal, Quebec, Canada;

and **Department of Oncology, M cGill University,

Montreal, Quebec, Canada

The mammary-derived growth inhibitor (MDGI) gene is a candidate tumor suppressor gene for human breast cancer. It has been shown to reduce the tumorigenicity of breast cancer cell lines in nude mice, and loss of expression of this gene has been shown in primary breast tumors. Furthermore, the human MDGI gene has been mapped to human chromosome 1p32-p35, a common region of deletion in sporadic breast tumors. We have determined the genomic structure of the human MDGI gene from a cosmid clone mapping to chromosome 1p32-p35 and have more finely mapped the MDGI gene relative to chromosome 1p microsatellite markers. The gene covers approximately $8 \mathbf{~ k b}$ of genomic DNA and is divided into four exons. In an attempt to identify possible inactivating mutations in the MDGI gene in human breast cancer, we have sequenced all four exons and their surrounding splice junctions in $\mathbf{3 0}$ sporadic breast tumors. Ten of these tumors showed loss of heterozygosity (LOH) in the 1p32-p35 region, with 5 tumors showing $\mathrm{LOH}$ in the subregion containing the MDGI gene. No mutations were found in this analysis. A polymorphism was identified in exon 2 in the constitutional DNA of 1/30 cases in this study, which resulted in the conversion of a lysine to an arginine residue at codon 53 . This variant was present in the constitutional DNA of a further $3 / 26$ women with sporadic breast cancer and $2 / 90$ control individuals ( $P$ $=0.20)$. Despite experimental evidence that MDGI

\footnotetext{
${ }^{1}$ To whom correspondence should be addressed at Division of Medical Genetics, Room L 1-425, Montreal General Hospital, 1650 Cedar Avenue, Montreal, H3G1A4, Quebec, Canada. Telephone: (514) 9376011, ext. 4201. Fax: (514) 934-8273.
}

has tumor suppressor activity, our data suggest that mutations in the coding region are uncommon in human breast tumorigenesis.

\section{INTRODUCTION}

Breast cancer is a common neoplasm affecting women in the western world. The frequency of loss of heterozygosity ( $\mathrm{LOH}$ ) at different chromosomal loci in sporadic breast tumors suggests that a number of tumor suppressor genes are involved in the development of the disease (Callahan et al., 1992). One such gene may bethe mammary-derived growth inhibitor (MDGI) gene, which is located at 1p32-p35 (Hung et al., 1995), a common region of loss in sporadic breast cancer (Borg et al., 1992; Bieche et al ., 1993, 1994; Munn et al ., 1995).

Based on the complete cDNA and protein homologies between the mouse MDGI and fatty acid-binding protein 3-muscle and heart (FABP3) genes (Yang et al., 1994; Treuner et al., 1994), it is assumed that these are the same genes. F urthermore, two independent reports have mapped the human FABP3 and MDGI genes to the same region of chromosome 1 (1p32-p35) (Troxler et al., 1993; Hung et al., 1995), providing further evidence that the human FABP3 and MDGI genes are identical.

MDGI was first identified as a growth inhibitor in lactating bovine mammary gland and was shown to play a role in mammary gland differentiation (Böhmer et al., 1987; Spener et al., 1990; Grosse et al., 1991). Recent studies on the transfection of an MDGI expression construct into breast cancer cell lines have shown reduced proliferation, promotion of cellular differentia- 
tion (Yang et al., 1994), and reduced tumor formation in nude mice (compared to mock-transfected or untransfected controls) (Hung et al., 1995). I mmunostaining of sections of human breast tumors showed loss of immunoreactive FABP3 protein in the neoplastic cells compared to its presence in adjacent normal epithelial cells (Hung et al., 1995). Together these data suggest that MDGI/FABP3 is a candidate tumor suppressor gene involved in breast cancer.

We have previously isolated a cosmid clone containing the entire MDGI gene (Hung et al., 1995). In this report we describe the genomic structure of this gene, including the number of exons, intron sizes, and sequence and location of intron/exon boundaries. We also map the gene relative to chromosome 1p microsatellite markers. To determine if human breast tumors contain inactivating mutations in the MDGI/FABP3 gene, we have sequenced the entire coding region of the gene including intron/exon boundaries in 30 sporadic breast tumors, 5 of which show loss of heterozygosity at microsatellite markers in the region containing the MDGI gene.

\section{MATERIALS AND METHODS}

Cloning and characterization of the human MDGI gene A single cosmid clone (MDGI .3) containing the entire MDGI gene was isolated as described previously (Hung et al., 1995). Sequencing of segments of this clone was performed using an $A B I 373 A$ automated sequencer using the methodology of Chen et al . (1993). The entire MDGI/FABP3 gene was sequenced in addition to a few kilobases of the flanking regions on both sides of the gene. The TED and autoTED programs (Gleeson and Hiller, 1991) edited the primary DNA sequence data. Assembly of the data was performed using the XBAP program of the Staden package (Dear and Staden, 1991). Alignments to known sequences and further analysis of the sequence were performed using the GCG sequence analysis software (University of Wisconsin Genetics Computer Group). The gene sequence revealed $100 \%$ identity with the previously published FABP3 cDNA. Intron/exon boundaries were determined by comparing the sequence of the FABP3 CDNA and the cosmid clone (MDGI.3). The MDGI/FABP3 genomic sequence is available in GenBank, and the structure is shown in Fig. 1. The intron/exon border sequences are given in Table 1, with exon sizes given in Table 2.

Patient material. The 30 tumors in this study were obtained from surgery prior to irradiation and chemotherapy and immediately frozen at $-70^{\circ} \mathrm{C}$. Peripheral blood was also collected for each case. Twenty-four cases were collected at the Karolinska Hospital, Stockhol $\mathrm{m}$, Sweden and the remaining six cases at Duke University Medical Centre, North Carolina, USA. DNA was isolated from the tumor tissue and blood by standard techniques (Larsson et al., 1990; F utreal et al., 1992). Histopathological examination of tumor tissue was performed on tumor pieces adjacent to those studied, and classification was made according to the World Health Organization guidelines (Hutter, 1987). Seventeen of the 30 tumors were ductal, 3 mucinous, 3 medullary, 2 lobular, 2 papillary, 1 comedo, and 2 of unknown histopathological subtype. The tumors were of malignancy stages I, $\mathrm{II}$, or III, and the age of onset of breast cancer in the 30 women varied from 30 to 71 years.

Control population. The control population consisted of 90 Swedish individuals aged 50 and above who have shown no signs of breast cancer.

Loss of heterozygosity analysis of $1 p$. The following polymorphic microsatellite repeat markers from the 1p32-p35 region were typed on the constitutional and tumor DNA of the 30 sporadic breast cancer cases shown in Table 1: D1S233, L-MYC, D1S197, D1S209, D1S438, and D1S207 (Fig. 2). The oligonucleotide primer sequences, allele sizes, and order of markers along the chromosome are according to the Généthon genetic linkage map (Gyapay et al., 1994). Genomic DNA (100 ng) was amplified by PCR in $50 \mathrm{mM} \mathrm{KCl}, 10 \mathrm{mM}$ Tris$\mathrm{HCl}, \mathrm{pH} 9.0,1.0-2.0 \mathrm{mM} \mathrm{MgCl}$ (BRL) (depending on primer set),

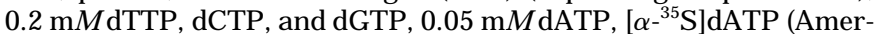
sham) at $1 \mu \mathrm{Ci} /$ reaction, and 2 units of Taq DNA polymerase (BRL) in a final volume of $25 \mu \mathrm{l}$. Thermocycling conditions consisted of 35 cycles of $40 \mathrm{~s}$ at $94^{\circ} \mathrm{C}, 40 \mathrm{~s}$ at $55 / 58^{\circ} \mathrm{C}$ (depending on primer set), and $40 \mathrm{~s}$ at $72^{\circ} \mathrm{C}$, followed by one cycle of 3-min extension at $72^{\circ} \mathrm{C}$. Reaction products were then diluted 1:2 with a stop buffer $(90 \%$ formamide, $10 \mathrm{mM}$ EDTA, bromophenol blue, and xylene cylanol) and heated to $94^{\circ} \mathrm{C}$ for $10 \mathrm{~min}$ prior to loading on $6 \%$ polyacrylamide sequencing gels. Gels were dried at $80^{\circ} \mathrm{C}$ and exposed to Kodak XAR5 film.

Fine mapping of the MDGI/ FABP3 gene relative to 1p microsatellite markers. A Research Genetics PCR-based radiation hybrid panel was used to map the gene relative to the microsatellite markers used for the LOH analysis. Exon 2 of MDGI/FABP3 (primers described below) and the microsatellite markers (above) were amplified in each of the hybrid DNAs (according to the manufacturer's instructions). By combining the data on chromosome 1p Généthon microsatellite markers previously run on the panel (accessed at the following web site address: ftp://shgc.stanford.edu/pub/hgmc/RH_data/ rh scores) and the data generated from this study, a common chromosomal region was identified. The region of common overlap suggested that MDGI was located centromeric to D1S233 and telomeric to MYCL1, as shown in Fig. 2.

Direct sequencing of the MDGI/ FABP3 gene in sporadic tumors. To sequence the gene, oligonucleotide primers were designed for flanking intron sequences for each exon, so as to include intron/exon splice sites. Double-stranded DNA was PCR amplified for each exon, with the anti-sense primer 5'-biotinylated. Each reaction consisted of 35 cycles in a Perkin-EImer 9600 thermocycler (Perkin-EImer/ Cetus), employing the following temperatures and times: denaturation, $94^{\circ} \mathrm{C}$ for $40 \mathrm{~s}$; annealing, $58^{\circ} \mathrm{C}$ (exons 2, 3, and 4 ) $/ 60^{\circ} \mathrm{C}$ (exon 1) for $40 \mathrm{~s}$; and elongation, $72^{\circ} \mathrm{C}$ for $40 \mathrm{~s}$. The primer sequences and sizes of amplified products for each exon are given in Table 3. The PCR products were then purified by agarose gel electrophoresis, and the band of appropriate size was excised from the gel. The DNA was isolated from the gel by freeze/thawing (Phelan et al., 1995), and the bi otinylated DNA was bound to strepavidin beads (Dynabeads, Dynal AS, Norway). Single-stranded DNA was then isolated by denaturing the DNA with $0.2 \mathrm{M} \mathrm{NaOH}$ and separating the nonbiotinylated DNA strand from the biotinylated (attached to the beads) using a magnetic rack (Magnetic Particle Concentrator, Dynal AS, Norway) (Phelan et al., 1995). Both strands were sequenced using the Sanger dideoxy method with a USB Sequenase Version $2.0 \mathrm{kit}$. (USB, OH). The sequencing reaction products were separated on $6 \%$ denaturing polyacrylamide gels. Gels were transferred to filter paper (Whatman) and dried prior to exposure to Kodak XAR-5 film.

Singlestrand confirmation (SSC) analysis of sequence variants. To determine the frequency of the sequence variant in exon 2, SSC analysis was developed for the exon 2 fragment. Genomic DNA (100 ng) was amplified using the exon 2 primers (Table 2) and under conditions as described above in the presence of $0.2 \mathrm{mM}$ dTTP, dCTP, and dGTP, $0.05 \mathrm{mM}$ dATP, $\left[\alpha^{-35} \mathrm{~S}\right] \mathrm{dATP}$ (Amersham) at $1 \mu \mathrm{Ci} / \mathrm{reac}-$ tion, and 2 units of Taq DNA polymerase (BRL) in a final volume of $12.5 \mu \mathrm{l}$. The reaction products were then diluted $1: 3$ with a stop buffer (described above) and heated to $94^{\circ} \mathrm{C}$ for $10 \mathrm{~min}$ prior to loading on $6 \%$ nondenaturing polyacrylamide gels with/without $5 \%$ glycerol. The gels were run at $4^{\circ} \mathrm{C}$ for $4-6 \mathrm{~h}$ and then were dried at $80^{\circ} \mathrm{C}$ and exposed to Kodak XAR-5 film.

\section{RESULTS}

The MDGI 3 cosmid cl one that contains the gene (see Materials and Methods) was sequenced, and alignment 

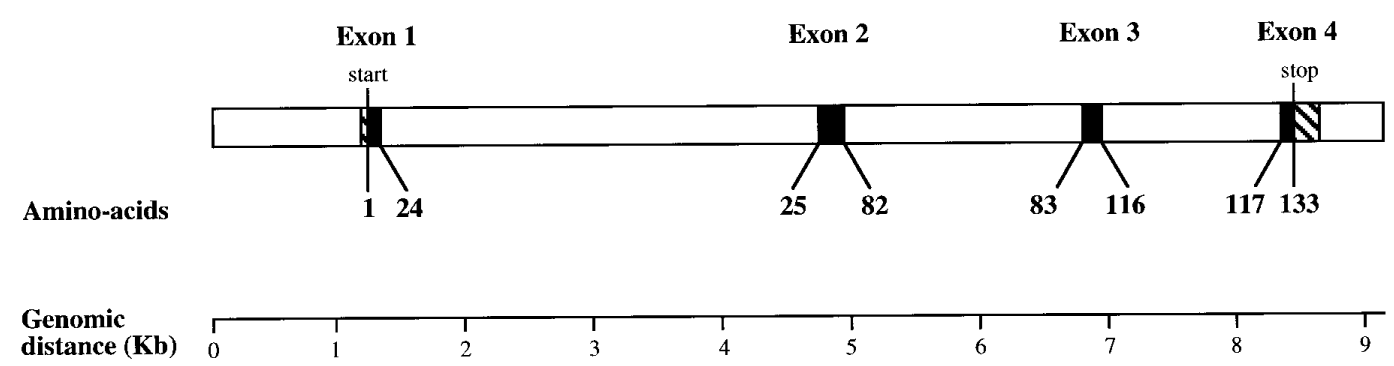

FIG. 1. Genomic structure of the human MDGI/FABP3 gene. The translated exons are depicted as solid boxes, the introns as open boxes, and untranslated exons as shaded boxes. The gene spans approximately $8 \mathrm{~kb}$ of genomic DNA. The translation start and stop sites are shown. Exon 1 spans 104 bp and contains the 5'-UTR region; exon 2, 173 bp; exon 3, 102 bp; and exon 4, 284 bp and the 3'-UTR region.

with the human FABP3 CDNA revealed 100\% identity in the coding regions, implying that $\mathrm{MDGI}$ and $\mathrm{FABP} 3$ are the same gene. This gene consists of four exons (exon 1, 104 bp; exon 2, 173 bp; exon 3, 102 bp; exon 4, $284 \mathrm{bp}$ ) and three introns (intron 1, $3.38 \mathrm{kp}$; intron 2, $1.89 \mathrm{~kb}$; intron 3, $1.44 \mathrm{~kb}$ ) spanning approximately $8 \mathrm{~kb}$ of genomic DNA (Fig. 1). Exons 1 and 4 contain approximately 40 and 210 bp of $5^{\prime}$ - and $3^{\prime}$-untranslated sequence, respectively. Each of the intron/exon boundaries was identified and sequenced (Table 1 ) to facilitate the search for mutations in the coding region and splice sites of the MDGI/FABP3 gene.

Six microsatellite repeat markers localized to chromosome 1p22-p35 (Fig. 2) (including the 1p32-p35 interval where MDGI/FABP3 has been mapped by FISH) were evaluated for $\mathrm{LOH}$ in the constitutional and tumor DNA of 30 breast cancer cases. Ten cases showed either complete or partial loss of this region (Fig. 2). Two cases appear to have shown LOH of the entire region (cases D3 and 100), while the remaining 8 cases showed partial losses involving both proximal portions (cases 8, 11, 36, 105, D177, and D176) and distal portions (cases D27, D49, D176) of this interval. This observation is consistent with previously published chromosome $1 p$ microsatellite $\mathrm{LOH}$ data in breast cancer (Hoggard et al., 1995). The localization of the MDGI/FABP3 gene relative to the microsatel lite repeat markers was determined using a PCR-based hybrid panel (Research Genetics) (see Materials and Methods). The gene appears to map between the loci of markers D1S233 and MYCL1, where five of the tumors (D3, 100, D176, D27, and D49) show LOH.

In an attempt to identify mutations in the MDGI/ FABP3 gene in 30 sporadic breast tumors, the four exons and flanking exon/intron junctions of this gene were sequenced (Tables 1 and 2). No mutations were found in the breast tumors. A single novel sequence polymorphism was identified (Fig. 3), which results in the conversion of lysine to arginine in codon 53 (the amino acid positions are according to Peeters et al. (1991). This rare polymorphic variant is found in 1/30 women included in this study and in the constitutional DNA of a further $3 / 26$ women with sporadic breast cancer (data not shown). The variant was also detected in the constitutional DNA of 2/90 control individuals ( $P$ $=0.20$ ), who do not have breast cancer (Fig. 3).

\section{DISCUSSION}

The MDGI/FABP3 gene has been demonstrated to have tumor suppressor activity in breast cancer in the following ways (Böhmer et al., 1987; Hung et al ., 1995). (1) In vitro studies involving transfection of an MDGIexpression construct into MCF-7 breast cancer cell lines resulted in reduced proliferative rates, altered morphology, and differentiation, compared to mocktransfected controls. (2) Transfected breast cancer cell lines also showed a reduced ability to form tumors in nude mice compared to the untransfected controls (Hung et al., 1995). (3) I mmunostaining with an antiFABP3 antibody revealed lack of expression of the protein in neoplastic breast cells compared to adjacent normal epithelia consistent with a role in breast tumor devel opment (Hung et al., 1995). In addition, the treatment of mouse mammary epithelial cells with antisense MDGI phosphorothioate oligonucleotides resulted in an inhibition of DNA synthesis, suppression of alveolar budding, and impaired $\beta$-casein synthesis, suggesting a block in cell differentiation (Yang et al., 1994).

We have elucidated the complete sequence and genomic structure of the human MDGI/FABP3 gene (Fig.

TABLE 1

Intron/Exon Border Sequences

\begin{tabular}{|c|c|c|c|}
\hline Intron & $\begin{array}{l}\text { Intron size } \\
\text { (bp) }\end{array}$ & $5^{\prime}$ junction sequence & $3^{\prime}$ junction sequence \\
\hline 1 & 3385 & ATGAAGTCACTCGgtgagcaagccgcggggctcagga & tatactcataaccttccccctaccctcagGTGTGGGTTTTG \\
\hline 2 & 1890 & AGGAAGGTCAAGgtaagtcaggaaacaggggtgggg & agctcaggcctctaccetctttccacagTCCATTGTGACAC \\
\hline 3 & 1443 & AAACTCATCCTGgtaagatgggcaactttggagctatatct & ccCccatctcactctgtctttccttccagACACTCACCCACG \\
\hline
\end{tabular}




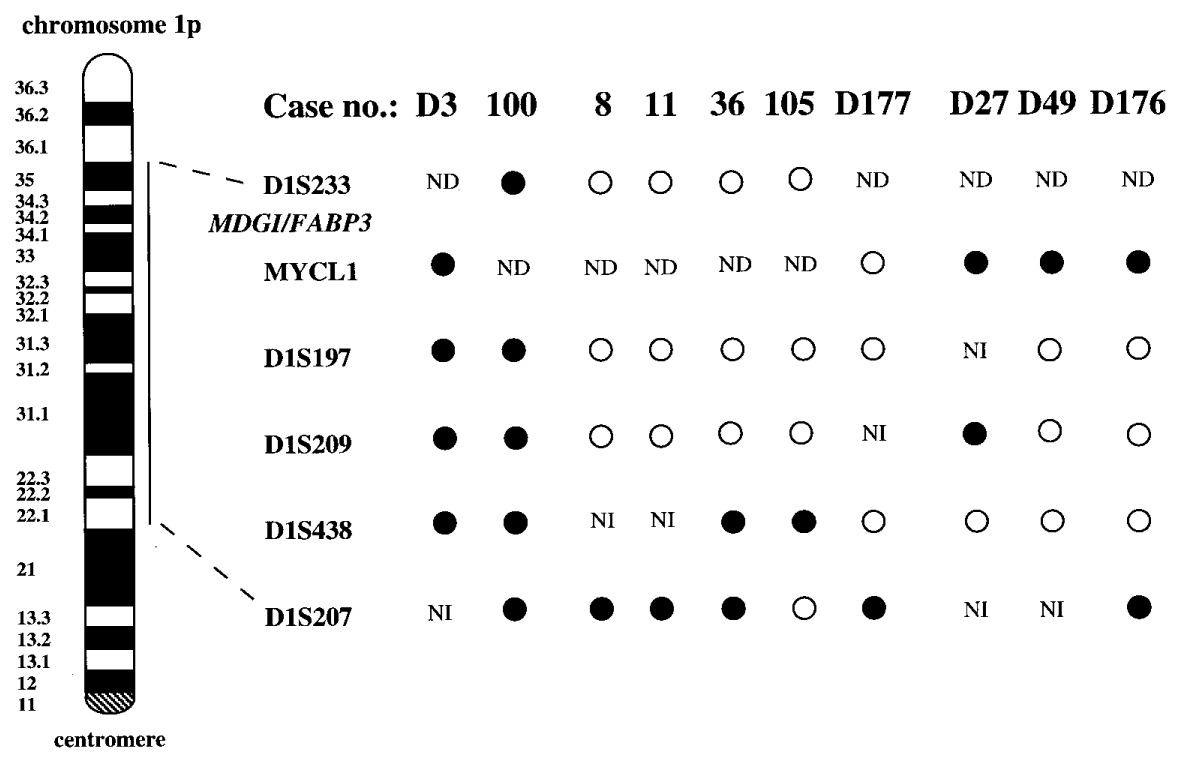

FIG. 2. A summary of loss of heterozygosity ( $\mathrm{LOH}$ ) results of six microsatellite repeat markers mapping to $1 \mathrm{p} 22-\mathrm{p} 35$ for 10 cases of sporadic breast cancer. The marker loci and their order are given to the right of the chromosome. Solid circles denote LOH; open circles denote retention of both alleles. The case numbers for each tumor are given at the top of the figure: cases 8, 11, 36, 100, and 105 are from the Karolinska Hospital; cases D3, D27, D49, D176, and D177 are from Duke University. NI, noninformative, ND, not determined.

1) so as to sequence all exons and their corresponding splice junctions to identify potential inactivating mutations in 30 sporadic breast cancers. The MDGI/FABP3 gene has been previously localized by FISH to 1p32p35 (Troxler et al., 1993; Hung et al., 1995). We have more finely mapped the gene relative to $1 p$ microsatellite markers in this region between D1S233 and MYCL 1, consistent with the cytogenetic localization. This report and others have shown LOH in breast tumors in this region, suggesting that this chromosomal region may harbor tentative tumor suppressor genes. These studies have shown varying $\mathrm{LOH}$ frequencies ranging from 21 to $62 \%$ (Borg et al., 1992; Bieche et al ., 1993; Munn et al., 1995) and complicated patterns of allele loss (Hoggard et al., 1995).

Tumor suppressor genes are thought to induce cancer by being inactivated, often by loss of one allele and mutation of the other (Knudson, 1993). It is expected that tumors showing loss of the first allele (as shown by LOH studies) are more likely to harbor point mutations in the second allele (Ruttledge et al., 1994). Elucidation of the genomic structure of the human MDGI/ FABP3 gene allowed us to look for mutations in the constitutional and tumor DNA of 5 breast tumors showing $\mathrm{LOH}$ in the MDGI region (Fig. 2). In addition, we sequenced 25 tumors that appeared to show retention of this region. No mutations were found. The lack of gene mutation in these 30 breast tumors suggests that this is not a common mechanism of inactivation of MDGI/FABP3 in these neoplasms.

The rare exon 2 polymorphism was observed more frequently (4/56) in breast cancer cases than in controls $(2 / 90)(P=0.20)$ (see Results). This missense amino acid change (lysine to arginine) affects a highly conserved residue at codon 53 in one of the protein's two fatty-acid binding sites (Offner et al., 1988). The significance of this observation is the subject of further investigation. The detection of the rare polymorphism in exon 2 proved that our technique was sensitive and efficient (Fig. 3). Thus, we feel it is unlikely that small deletions and insertions or other single base substitutions would have escaped our detection. We also have analyzed 18 breast cancer cell lines for homozygous deletions of human MDGI/FABP3, using PCR amplification of exon 2 and an internal control from chromosome 22, but none were found (data not shown).

TABLE 2

Oligonucleotide Primers Used for SSC and Sequencing Analysis

\begin{tabular}{ccccc}
\hline Exon No. & $\begin{array}{c}\text { Exon size } \\
\text { (bp) }\end{array}$ & Sense primer & Antisense primer & $\begin{array}{r}\text { Size of PCR } \\
\text { product (bp) }\end{array}$ \\
\hline 1 & 104 & $5^{\prime}$-cctggggcttcctatttc-3' & $5^{\prime}$-caagccaacatcctgagc-3' & 261 \\
2 & & & $5^{\prime}$-cttcatgtagtcatagaa-3' & 271 \\
3 & 173 & $5^{\prime}$-tgtacactgcttctctaccc-3' & $5^{\prime}$-gtctcagcactctccattcc-3' & 160 \\
4 & 102 & $5^{\prime}$-tcacagctcaggctctacc-3' & $5^{\prime}$-gatatagcgccaaagttgcc-3' & 402 \\
\hline
\end{tabular}




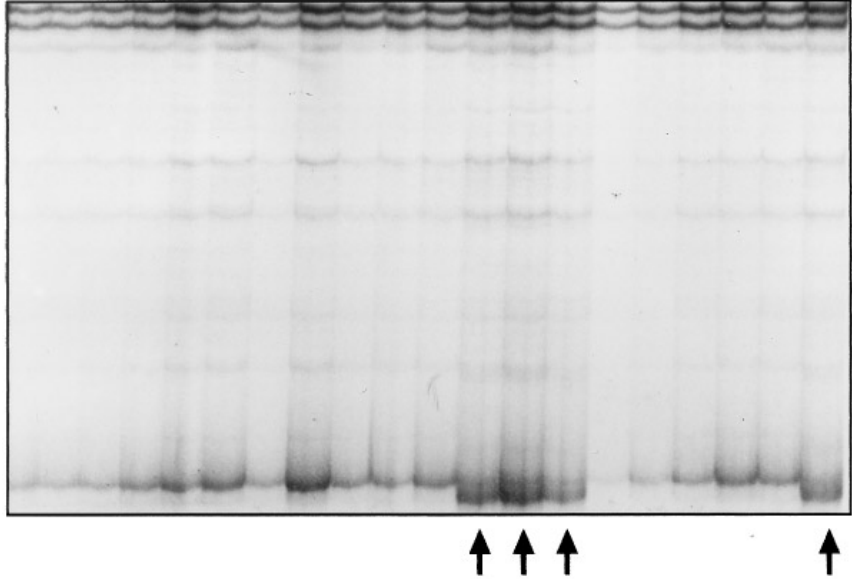

FIG. 3. Single-strand confirmational (SSC) analysis of constitutional DNA from 20 women with breast cancer showing 4 cases in which the codon 53 polymorphism was identified, as indicated by the arrows at the bottom of the figure.

In conclusion, although transfection experiments provide biological evidence for a suppressor activity of MDGI/FABP3 in breast cancer, we did not observe structural mutations in the coding region of the MDGI/ FABP gene in 30 sporadic breast tumors. However, this finding is not unprecedented. Loss of expression of the breast- ovarian cancer gene BRCA1 has been reported in sporadic breast cancers (Thompson et al., 1995) but no point mutations have been found in 32 cases of sporadic human breast tumors, all of which show $\mathrm{LOH}$ at the BRCA1 gene (Futreal et al., 1994). It may be possible that the MDGI/FABP3 gene is not the target of losses of the 1p32- p35 region. On the other hand, alternative mechanisms may result in the loss of gene expression, including alterations in the methylation of the promoter. This phenomenon has been observed in the von Hippel Lindau gene (VHL) (Herman et al., 1994) and the retinoblastoma gene (RB) (Ohtani-F ujita et al., 1993). The evidence for decreased expression of MDGI in human breast cancer motivates further work regarding promoter methylation and regulation of expression of MDGI.

\section{ACKNO WLEDGMENTS}

Wethank Shyam Rangaratnam for technical assistance. This work was supported by the Department of the Army Grants DAMD17-J 4299, the Fonds de la Recherche en Sante du Quebec (FRSQ), and the Canadian Genetic Diseases Network of Centres of Excellence. C.L. and C.P. were funded by the Swedish Cancer F oundation. M.P. was funded by a grant from the National Cancer Institute of Canada. P.T. is a Medical Research Council and Cancer Research Society of Canada Scholar. M.H.R. is supported by a long-term fellowship from the International Human Frontier Science program.

\section{REFERENCES}

Bieche, I., Champene, M., and Lidereau, R. (1994). A tumour suppressor gene on chromosome 1p32- pter controls the amplification of myc family genes in breast cancer. Cancer Res. 54: 4274-4276.
Bieche, I., Champene, M., Matifas, F., Cropp, C., Callehan, R., and Lidereau, R. (1993). Two distinct regions involved in 1p deletion in human primary breast cancer. Cancer Res. 53: 1990- 1994.

Böhmer, F., Kraft, R., Otto, A., Wernstedt, C., Hellman, U., Kurtz, A., Muller, T., Rodhe, K., Etzold, G., Lehmann, W., Langen, P., Heldin, C., and Grosse, R. (1987). Identification of a polypeptide growth inhibitor from bovine mammary gland. J . Biol. Chem. 262: 15137- 15143 .

Borg, A., Zhang, Q.-X., Olsson, H., and Wenngren, E. (1992). Chromosome 1 alterations in breast cancer: Allelic loss on $1 p$ and $1 q$ is related to lymphogenic metastases and poor prognosis. Genes Chromosomes Cancer 5: 311-320.

Callahan, R., Cropp, C., Merlo, G., Liscia, D., Cappa, A., and Lidereau, R. (1992). Somatic mutations and human breast cancer: A status report. Cancer 69: 1582-1588.

Chen, E., Schlessinger, D., and Kere, J. (1993). Ordered shotgun sequencing, a strategy for integrated mapping and sequencing of YAC clones. Genomics 17: 651- 656.

Dear, S., and Staden, R. (1991). A sequence assembly and editing program for efficient management of large projects. Nucleic Acids Res. 19: 3907- 3911.

Futreal, P., Liu, Q., Shattuck-Eidens, D., Cochran, C., Harshman, K., Tavtigian, S., Bennett, L., Haugen-Strano, A., Swensen, J ., Miki, Y., Eddington, K., McLure, M., Frye, C., Weaver-Feldhaus, J ., Ding, W., Gholami, Z., Söderkvist, P., Terry, L., J hanwar, S., Berchuck, A., I glehart, J ., Marks, J . D. G., Barrett, J ., Skolnick, M., Kamb, A., and Wiseman, R. (1994). BRCA1 mutations in primary breast and ovarian carcinomas. Science 266: 120- 122.

Futreal, P., Soderkvist, P., Marks, J ., I glehart, J ., Cochran, C., Barrett, J ., and Wiseman, R. (1992). Detection of frequent allelic loss on proximal chromosome $17 q$ in sporadic breast carcinoma using microsatellite length polymorphisms. Cancer Res. 52: 2624- 2627.

Gleeson, R., and Hiller, L. (1991). A trace display and editing program for data from fluorescence based sequencing machines. Nucleic Acids Res. 19: 6491-6493.

Grosse, R., Böhmer, F.-D., Binas, B., Kurtz, A., Spitzer, E., Muller, T., and Zschiesche, W. (1991). Mammary-derived growth inhibitor (MDGI). In "Genes, Oncogenes and Hormones: Advances in CelluIar and Molecular Biology of Breast Cancer" (R. B. D. a. M. E. Lippman, Ed.), pp. 69-96, Kluwer Academic, Boston.

Gyapay, G., Morisette, J ., Vignal, A., Dib, C., Fizames, C., Millasseau, P., Marc, Bernardi, G., Lathrop, M., and Weissenbach, J . (1994). The 1993- 94 Généthon human genetic linkage map. Nature Genet. 7: 246- 339.

Herman, J., Latif, F., Weng, Y., Lerman, M., Zbar, B., Liu, S., and Samid, D. (1994). Silencing of the VHL tumour suppressor gene by DNA methylation in renal carcinoma. Proc. Natl. Acad. Sci. USA 91: 9700-9704.

Hoggard, N., Brintnell, B., Howell, A., Weissenbach, J ., and Varley, J. (1995). Allelic imbalance on chromosome 1 in human breast cancer. II. Microsatellite repeat analysis. Genes Chromosomes Cancer 12: 24- 31.

Hung, H., Larsson, C., Narod, S., and Pollak, M. (1995). Tumour suppressor activity of the gene encoding mammary-derived growth inhibitor. Cancer Res. 55: 2225- 2231.

Hutter, R. (1987). Worldwide agreement on the staging of cancer. Arch. Surgery 122: 1235-1246.

Knudson, A. (1993). Antioncogenes and human cancer. Proc. Natl. Acad. Sci. USA 90: 10914-10921.

Larsson, C., Byström, C., Skoog, L., Rotstein, S., and Nordenskjöld, M. (1990). Genomic alterations in human breast carcinomas. Genes Chromosomes Cancer 2: 191- 197.

Munn, K., Walker, R., and Varley, J . (1995). Frequent alterations of chromosome 1 in ductal carcinoma in situ of the breast. Oncogene 10: 1653-1657.

Offner, G., Brecher, P., Sawlivich, W., Costello, C., and Troxler, R. 
(1988). Characterization and amino acid sequence of a fatty acidbinding protein from human heart. Biochem. J . 252: 191- 198.

Ohtani-Fujita, N., Fujita, T., Aoike, A., Osifchin, N., Robbins, P., and Sakai, T. (1993). CpG methylation inactivates the promoter activity of the human retinoblastoma tumour suppressor gene. Oncogene 8: 1063- 1067.

Peeters, R., Veerkamp, J ., van Kessel, A., Kanda, T., and Ono, T. (1991). Cloning of the cDNA encoding human skeletal-muscle fatty-acid binding protein, it's peptide sequence and chromosomal localization. Biochem. J . 276: 203- 207.

Phelan, C., Liu, L., Ruttledge, M., Müntzning, K., Ridderheim, P.-A., and Collins, V. (1995). Chromosome 17 abnormalities and lack of TP53 mutations in paediatric central nervous system tumours. Hum. Genet. 96: 684- 690.

Ruttledge, M., Sarrazin, J ., Rangaratnam, S., Phelan, C., Twist, E., Merel, P., Delattre, O., Thomas, G., Nordenskjöld, M., Collins, V., Dumanski, J ., and Rouleau, G. (1994). Evidence for the complete inactivation of the neurofibromatosis type 2 gene in the majority of sporadic mengiomas. Nature Genet. 6: 180-184.
Spener, F., Unterberg, C., Börchers, T., and Grosse, R. (1990). Characteristics of fatty acid-binding proteins and their relation to mammary-derived growth inhibitor. Mol. Cell. Biochem. 98: 57-68.

Thompson, M., J ensen, R., Obermiller, P., Page, D., and Holt, J . (1995). Decreased expression of BRCA1 accelerates growth and is often present during sporadic breast cancer progression. Nature Genet. 9: 444-450.

Treuner, M., Kozak, C., Gallahan, D., Grosse, R., and Muller, T. (1994). Cloning and characterization of the mouse gene encoding mammary-derived growth inhibitor/heart-fatty acid-binding protein. Gene 147: 237- 242.

Troxler, R., Offner, G., J iang, J ., Wu, B., Skare, J ., Milunsky, A., and Wyandt, H. (1993). Localization of the gene for human heart fatty acid binding protein to chromosome 1p32- 1p33. Hum. Genet. 92: 563- 566.

Yang, Y., Spitzer, E., Kenney, N., Zschiesche, W., Li, M., Kromminga, A., Muller, T., Spener, F., Lezius, A., Veerkamp, J., Smith, G., Salomon, D., and Grosse, R. (1994). Members of the fatty acid binding protein family are differentiation factors for the mammary gland. J . Cell Biol. 124: 1097- 1109. 